TI 2011-055/1

Tinbergen Institute Discussion Paper

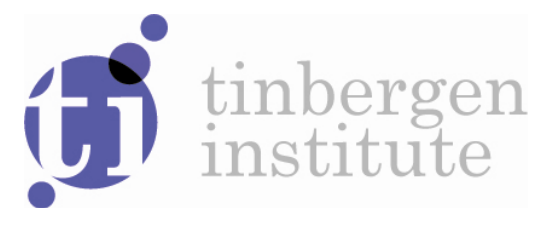

Power and the Privilege of Clarity:

An Analysis of Bargaining Power and Information Transmission

Adrian de Groot Ruiz

Theo Offerman

Sander Onderstal 
Tinbergen Institute is the graduate school and research institute in economics of Erasmus University Rotterdam, the University of Amsterdam and VU University Amsterdam.

More TI discussion papers can be downloaded at http://www.tinbergen.nl

Tinbergen Institute has two locations:

Tinbergen Institute Amsterdam

Gustav Mahlerplein 117

1082 MS Amsterdam

The Netherlands

Tel.: +31(0)205251600

Tinbergen Institute Rotterdam

Burg. Oudlaan 50

3062 PA Rotterdam

The Netherlands

Tel.: +31(0)10 4088900

Fax: $+31(0) 104089031$

Duisenberg school of finance is a collaboration of the Dutch financial sector and universities, with the ambition to support innovative research and offer top quality academic education in core areas of finance.

DSF research papers can be downloaded at: http://www.dsf.nl/

Duisenberg school of finance

Gustav Mahlerplein 117

1082 MS Amsterdam

The Netherlands

Tel.: +31(0)20 5258579 


\title{
Power and the Privilege of Clarity: An Analysis of
}

\section{Bargaining Power and Information Transmission*}

\author{
Adrian de Groot Ruiz ${ }^{\mathrm{a}}$, Theo Offerman ${ }^{\mathrm{b}}$ and Sander Onderstal $^{\mathrm{b}}$
}

July 25, 2012

\begin{abstract}
People in inferior bargaining positions are often vaguer when they express their preferences. In this paper, we explain how power shapes clarity of communication. We analyze information transmission in a cheap talk bargaining game between an informed Sender and an uninformed Receiver. Our main result is that the maximum amount of information transmission is increasing in the relative power of the Sender. As a result, clarity is a privilege of the powerful. In our model, only Senders whose preferences are closely aligned with the Receiver can completely reveal their information in equilibrium. We discuss some testable implications of our model.
\end{abstract}

KeYwords: Cheap Talk, Clarity, Power, Bargaining, Information Transmission.

\footnotetext{
${ }^{*}$ We would like to thank seminar participants at New York University, Radboud University Nijmegen, the University of Amsterdam, the MBEES workshop 2011 in Maastricht, Erasmus University Rotterdam, and the 2012 ESA meeting in New York City. Financial support from the Dutch Science Foundation (NWO-VICI 453-03-606) and from the Amsterdam Research Priority Area Behavioral Economics is gratefully acknowledged.

${ }^{a}$ Department of Economics, Institute for Management Research, Radboud University Nijmegen, P.O, Box 9108, 6500 HK Nijmegen, the Netherlands; a.grootruiz@fm.ru.nl.

${ }^{\mathrm{b}}$ Faculty of Economics and Business, University of Amsterdam, Roetersstraat 11, 1018 WB, the Netherlands; T.J.S.Offerman@uva.nl, onderstal@uva.nl.
} 


\section{Introduction}

Clarity seems to be a privilege of the powerful. The less fortunate among us are typically vaguer about their desires and need to think harder about what they say or do not say. Social psychologists have found that workers are more assertive in communicating their desires towards lower ranked co-workers than towards higher ranked co-workers (Kipnis, Schmidt and Wilkinson (1980), Yukl and Falbe (1990)). Gender studies point to a similar pattern in patriarchal societies, where women are found to be more hesitant in stating their wishes and interests than men. ${ }^{1}$ The relation between power and clarity could be shaped primarily by history and culture. In the communication literature, the link between power and communication is widely recognized (Keating, 2009) and believed to be strongly mediated by culture (Gudykunst and Lee, 2003). High status individuals are typically approached with more respect and too clear a message by a lower ranked individual about her preferences might simply be seen as 'disrespectful.' Similarly, direct communication of preferences may result in the loss of face of the powerful person if it openly contradicts her wishes or of the less powerful person if her wishes are ignored. In contrast to the above disciplines, in economics the relation between power and communication is a largely untouched research area. ${ }^{2}$

In this paper, we explore the possibility that there is a fundamental strategic foundation for the relation between power and clarity. We focus on bargaining under asymmetric information, as this is a common type of interaction where clarity matters. One can think of labor negotiations between managers and

\footnotetext{
${ }^{1}$ When discussing the source of miscommunication between men and women, some authors emphasize the role of power relations while others stress the role of culture (Baer (1976), Butler (1976), Maltz and Borker (1982), Henley and Kramarae (2001)).

${ }^{2}$ As far as we know, in economics the only research touching on this subject concerns how the level of connectedness in a network affects the bargaining power of individuals in bilateral negotiations (Calvó-Armengol, 2001).
} 
employees, divorce negotiations between men and women, or multinationals bargaining about merger remedies with a competition authority.

How does power come into play in such situations? Importantly, the consequences of disagreement differ among agents with different levels of power. Simply put, agents in a more powerful position have better outside options. This power can firstly be due to institutional or cultural rules. For instance, central banks are more powerful if they are backed up by strict laws. Similarly, a manager is more powerful in countries where employees can be fired easily (such as the US) than in countries where employees have lots of protection (such as France). Finally, in countries with Islamic law, men have more rights than women at divorce, whereas in most Western countries women tend to have at least equal rights at divorce. Secondly, power can come from social, political or economic resources. For instance, a worker has more bargaining power if the labor market is tight. And even in communities where women have equal legal rights but tend to work in unpaid jobs, men tend to have a superior economic position when filing for divorce. In sum, power affects the costs of disagreeing for agents in bargaining settings.

We think about clarity as informational clarity: how much does someone learn about the state of the world from a message? The informational clarity of a message can firstly depend on its literal clarity: the indirectness, inexplicitness, vagueness or ambiguity of the words used (Cheng and Warren (2003), Agranov and Schotter (2010)). ${ }^{3}$ In a single interaction with a stranger from a culture one does not know, the literal meaning is all one can go by. Secondly, if people share a cultural and social history, the information messages convey also depends on how messages are used. For instance, the precise statement "I'll come to your office at four o'clock" is in some (office) cultures not at all informative, because people use it under a wide range of intentions as when to come. By contrast, in some countries the ambiguous phrase "We may not appreciate it if your market share exceeds 25\%" can be highly informative if

\footnotetext{
${ }^{3}$ One may of course be mainly interested in literal clarity, for instance for linguistic purposes. We are chiefly interested in informational clarity as this determines the actions people take.
} 
such a formulation is only used when officials from the competition authority intend to reject the merger proposal. The more history people share, the more the clarity of messages will depend on their use. In equilibrium, informational meaning is completely determined by use: what message is used in what state of the world?

It is now possible to translate our original question of how power influences clarity into a precise one: how does bargaining power influence information transmission in equilibrium? We study this question in an elementary bargaining setting. A Sender with private preferences and a Receiver with commonly known preferences bargain over a one-dimensional issue. ${ }^{4}$ The Sender sends a costless message to the Receiver, after which they play an ultimatum game in which the Sender can reject or accept the proposal of the Receiver.

We find that bargaining power is a key determinant of how much information can be transmitted: information transmission is increasing in the Sender's power and decreasing in that of the Receiver. In other words, the higher the relative power of an informed agent, the clearer she will be. There is one exception: Senders who have no bargaining power can fully reveal their type since they will be offered the Receiver's preferred outcome anyway in equilibrium.

We see our results primarily as a proof-of-principle, as many power relations and strategic settings are more complex in practice. At the same time, we believe that the intuition behind our results holds more generally. If you hold little power, it is not in your best interest to reveal too much information, because that can be exploited. Hence, you had better be kind of vague and strategic about what you communicate. If you are powerful, the potential for exploitation is limited and you can afford to be clear.

In addition to shedding light on power relations, this paper contributes to the theoretical literature on bargaining and information transmission. Our model differs from previous models in that the private information of the

\footnotetext{
${ }^{4}$ We refer to the Sender as a 'she' and the Receiver as 'he.'
} 
Sender does not determine her bargaining power. This allows us to separate power from private preferences and model the power agents have due to their social, political or economic position irrespective of their preference in a particular situation. Our model is close to that of Matthews (1989), who was the first to study veto threats. In Matthews' model, however, the Sender's type determines her disagreement payoff, whereas in our model the disagreement payoff is an exogenous variable which is the same for all Sender types. Hence, we can model the power of a worker due to a tight labor market regardless of her preferences on unpaid leave or model the legal power divorcing men have in Saudi Arabia regardless of their individual preferences about how much they want to see their children.

Our modeling choice has profound implications for information transmission. Matthews finds that information transmission is fundamentally limited in his veto-setting, as the maximum equilibrium size is two in his model. From our results, we learn that this result hinges on the disagreement point being on the line. In our setup, a full range of Crawford-Sobel-like partition equilibria exists, allowing for more refined communication. In particular, the role of power in our model mirrors the role of interest-alignment in the Crawford-Sobel game to a large extent. Conceptually, the key difference is that Sender types whose preferred bargaining outcome is close to the Receiver's preferred outcome may completely reveal their information, whereas complete separation is never possible in the Crawford-Sobel model. ${ }^{5}$

The literature on economic bargaining and information transmission has mostly focused on buyer-seller situations, where the outcome-set is zero sum conditional on trade (e.g. Matthews and Postlewaite (1989) and Farrell and

\footnotetext{
${ }^{5}$ In our analysis, we look at standard preferences and do not take a possible aversion to lying (Kartik, Ottaviani and Squintani, 2007; Kartik 2009) into account. One justification would be that the Sender may send a message with a proposed action rather than one containing a claim about her type. We also abstract from endogenous reputation building that could arise in repeated interactions (Sobel, 1985).
} 
Gibbons (1989)). In these models, the bargaining power of the other party is typically unknown, so that power and private information again coincide. ${ }^{6,7}$

Finally, our model has various interesting applications. In the conclusion we discuss testable economic implications for labor contracts and for remedies merging firms propose to competition authorities.

The remainder of this paper has the following structure. Section 2 presents a simple example of our model that serves to illustrate our set-up and results. Section 3 presents the model and the results. Section 4 concludes. All proofs are relegated to the appendix.

\section{Example}

In this section, we consider a linear example to illustrate the main results from our general model.

\subsection{The model}

Consider a cheap talk game with veto threats between an informed Sender (she) and an uninformed Receiver (he). The outcome of the game $x$ is a point on the interval $[0,1]$ or the disagreement point $\delta \notin[0,1]$. The Sender's payoff on the interval depends on the state of the world $t$ (her type): $U^{S}(x, t)=-|x-t|$. The larger the distance between the outcome $x$ and her type $t$, the lower the Sender's payoff. The Sender is privately informed of her type $t$, while it is commonly known that $t$ is drawn from the uniform distribution on $[0,1]$. The Receiver's payoff, $U^{R}(x)=-x$, is independent of $t$ : he always prefers smaller outcomes to larger ones. We vary the payoff of the disagreement point to the players: $U^{R}(\delta)=-d^{R}$ and $U^{S}(\delta)=-d^{S}$ with $d^{R}, d^{S}>0$. Note that

\footnotetext{
${ }^{6}$ For a literature-review on bargaining with incomplete information see Ausubel, Cramton and Deneckere (2002).

${ }^{7}$ Interesting buyer-seller models exist that involve cheap talk under partially aligned interests, such as Pitchik and Schotter (1987), but those do not look at bargaining power.
} 
$d^{R}$ and $d^{S}$ are the size of the "harm" if bargaining breaks down. In particular, we have:

$$
\begin{gathered}
U^{R}(x)-U^{R}(\delta)=d^{R}-x \text { for all } x \in[0,1] \\
U^{S}(x, t)-U^{S}(\delta)=d^{S}-|x-t| \text { for all } x \in[0,1]
\end{gathered}
$$

Observe that the Receiver prefers $\delta$ to all outcomes more than $d^{R}$ away from the origin and that the Sender prefers $\delta$ to all outcomes on the line more than $d^{S}$ away from her type $t$.

The game proceeds as follows. First, the Sender is informed of her type $t$. Subsequently, she sends a costless message $m \in M$ to the Receiver, where $M$ is some sufficiently rich message set. Then, the Receiver proposes an action $a \in[0,1]$ to the Sender. Finally, the Sender accepts or rejects $a$. If she accepts, $x=a$ is the outcome and if she rejects, $x=\delta$ is the outcome.

The game is an elementary bargaining setting under asymmetric information and models some important aspects of real interactions. The one-dimensional bargaining set allows us to capture partially aligned and partially conflicting interests of the players. The one-sided information asymmetry and single round of 'pre-play communication' captures the essence of biased information transmission. The game is similar to Matthews' (1989), except that the disagreement point lies on the real line in Matthews' model. The disagreement point being now outside of the line allows us to model differences in bargaining power independent of player's preferences on the line. Hence, the disagreement payoff reflects power individuals have due to their (commonly known) social, political or economic position and which they share with other members of their group. The bargaining power of the players in our game is determined by how attractive the disagreement point $\delta$ is to them. As $d^{S}\left[d^{R}\right]$ becomes smaller, the Sender's [Receiver's] payoff of the disagreement point increases and the interval of points that the player prefers to $\delta$ narrows. Hence, the larger $d^{S}\left[d^{R}\right]$, the 
smaller the bargaining power of the Sender [Receiver]. Figure 1 illustrates the model.

Figure 1: A linear example

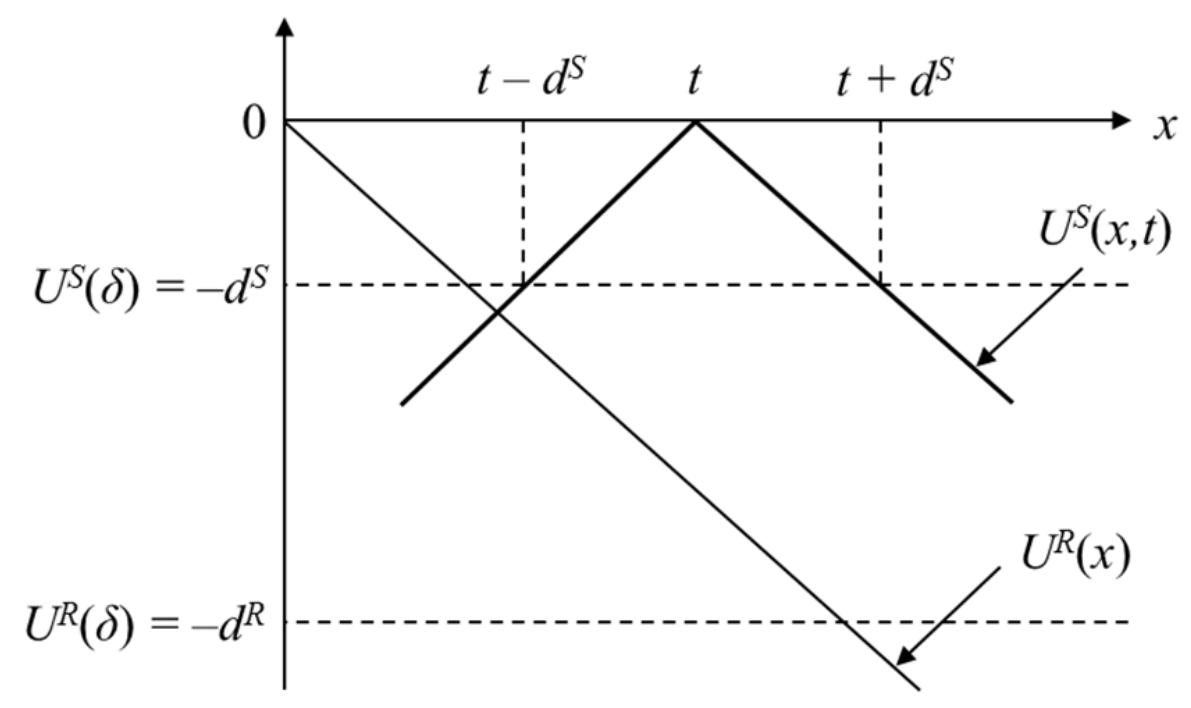

\subsection{Equilibria}

Like Matthews (1989), we employ a refinement of the perfect Bayesian equilibrium. First, we restrict the Receiver to play pure strategies. Second, we require that Sender types who plan to veto any equilibrium action send a message inducing an action $a$ that maximizes $U^{S}(a, t)$. This refinement is motivated on the basis of Selten's (1975) trembling hand perfection argument: the Sender considers that she might tremble with a small probability and accept the Receiver's proposed action. From now on we refer to a perfect Bayesian equilibrium satisfying these two requirements simply as an equilibrium.

To provide a formal description of an equilibrium, we introduce some additional notation. Let for any set $S, \Delta S$ denote the set of probability distributions on $S$. Let $T$ denote the Sender's type set and $A$ represent the set of actions for the Receiver. In the example, $T=A=[0,1]$. A strategy for the Sender consists of a message function $\mu: T \rightarrow \Delta M$ and an acceptance probability function $\nu: \mathbb{R} \times T \rightarrow[0,1]$. A strategy of the Receiver is a function 
$\alpha: M \rightarrow \mathbb{R}$. The Receiver has correct prior beliefs $\beta^{0}$. Finally, the Receiver has posterior beliefs $\beta: M \rightarrow \Delta T$.

Definition 1 An equilibrium $\sigma^{*}=\left\{\mu^{*}, \nu^{*}, a^{*}, \beta^{*}\right\}$ is characterized by the following four conditions:

1. For each message $m$, the Receiver chooses an action $\alpha^{*}(m)$ that maximizes his expected utility conditional on his posterior beliefs $\beta^{*}$ : $\alpha^{*}(m) \in \arg \max _{a \in A} E_{t}\left[\left(U^{R}(a)-U^{R}(\delta)\right) \nu(a, t) \mid \beta^{*}\right]$ for all $m$;

2. Each Sender type $t$ sends a message $m \in \mu^{*}(t)$ maximizing her utility: $m \in \underset{m \in M}{\arg \max } U^{S}\left(\alpha^{*}(m), t\right) \forall m$ in the support of $\mu^{*}(t) \forall t ;$

3. The Sender accepts the Receiver's action iff it gives her more utility than the disagreement point:

$\nu^{*}(a, t)=1$ if $U^{S}(a, t)>U^{S}(\delta)$ and $\nu^{*}(a, t)=0$ if $U^{S}(a, t)<U^{S}(\delta) ;$

4. $\beta^{*}$ is derived from $\mu^{*}$ and $\beta^{0}$ using Bayes' rule where possible.

Definition 2 An equilibrium $\sigma^{*}$ is called a partition equilibrium if there is a partition $0=t_{0}<t_{1}<\cdots<t_{n-1}<t_{n}=1$ of the type space such that for $k=1, \ldots, n$, each type in $\left(t_{k-1}, t_{k}\right)$ induces action an $a_{k}$ with $a_{1}<a_{2}<\ldots<a_{n}$.

As in Crawford and Sobel's (1982) and Matthews' (1989) cheap talk games, all equilibria of our game are partition equilibria. ${ }^{8}$ Each type induces that action that is closest to her type, so that the type space can be partitioned into intervals of types who induce the same action. The intuition for this result is the following. First of all, full separation is impossible in any type-interval contained in $\left(d^{S}, 1\right]$ : The utility for a revealed type $t \in\left(d^{S}, 1\right]$ would be equal to her utility from the disagreement point because the receiver will choose action $a=t-d^{S}$. As a consequence, the Sender has an incentive to mimic a higher type. More generally, it can be shown that there is a minimum distance be-

\footnotetext{
${ }^{8}$ To be precise, the action set characterizes an (infinite) class of essentially equivalent equilibria that induce the same equilibrium outcome and differ only in the messages that are used.
} 
tween any two equilibrium actions, so that the equilibrium action set is finite. Together with the fact that Senders elicit the action closest to their type, this results in a well-ordered partition.

The number of equilibrium actions $n$ is called the "size of the equilibrium". In games with only partition equilibria, the size of the equilibrium provides a natural measure of information transmission, which is invariant to scaling (of the payoff, action or type space). Equilibrium size will correlate well with other measures, such as conditional variance, prediction error, ex-ante efficiency or ex-post efficiency, with the suitability of each depending on the context. ${ }^{9}$ In all cheap talk games, a size-1 (pooling) equilibrium exists in which no information is transmitted. We say that more information is transmitted as the size of the equilibrium increases.

In this cheap talk barraging game, the most influential (most informative) equilibrium seems most plausible. Still, as in other continuous cheap talk games like that of Crawford and Sobel (1982) or Matthews (1989), the equilibrium set is hard to refine. ${ }^{10}$ In De Groot Ruiz, Offerman and Onderstal (2011a), we introduce the Average Credible Deviation Criterion and show that it selects a unique maximum-size equilibrium in the model presented in this paper (under some conditions). This criterion generalizes credible deviations approaches such as neologism proofness (Farrell, 1993) and announcement proofness (Matthews, Okuno-Fujiwara and Postlewaite, 1991) and does not suffer from non-existence. In an experiment, we find support for the predictions of ACDC in a setting pertaining to the model we present here (De Groot Ruiz, Offerman and Onder-

\footnotetext{
${ }^{9}$ A problem of these measures is that they lack a natural dimension, such that they are typically not invariant to immaterial transformations of the game. For instance, the average prediction error or the conditional variance is not invariant to scaling of the type space and exante utility is not invariant to immaterial transformation of payoffs of subsets of the type set. The fraction of outcomes that is ex-post efficient does not suffer from this invariance problem, but is a rather crude measure.

${ }^{10}$ Traditional signaling refinements in the vein of Kohlberg and Mertens (1986) have no bite in cheap talk games, as messages are costless. In De Groot Ruiz, Offerman and Onderstal (2011a), we show that in the current game also the cheap talk refinements neologism proofness (Farrell, 1993), announcement proofness (Matthews, Okuno-Fujiwara and Postlewaite, 1991), the recurrent mop (Rabin and Sobel, 1996) and NITS (Chen, Kartik and Sobel, 2008), are not selective and the non-equilibrium concepts of Credible Message Rationalizability (Rabin, 1990) and Partial Common Interest (Blume, Kim and Sobel, 1993) are not predictive.
} 
stal, 2011b). In particular, we find that the maximum size equilibrium organizes behavior best in all five games we study.

\subsection{Power and Clarity}

We now turn to the central question of this paper: How does power affect information transmission in equilibrium? To answer this question, let us study an example where we fix the Receiver's bargaining power by taking $d^{R}=\frac{5}{4}$ and increase the Sender's bargaining power by moving her disagreement point's "harm" from $d^{S}=\frac{1}{2}$ to $d^{S}=\frac{1}{4}$.

Let us start with $d^{S}=\frac{1}{2}$. This game has two equilibria, a size-1 equilibrium and a size-2 equilibrium. In the size-1 equilibrium, the Receiver ignores all Sender messages and best responds to his prior beliefs. His optimal action involves a trade-off between maximizing the probability that the proposal is accepted and maximizing the payoff of the proposal conditional on acceptance. Note that proposals $a>1-d^{S}=\frac{1}{2}$ are not optimal from the viewpoint of the Receiver because the proposal $a=\frac{1}{2}$ will be accepted by more Sender types and yields the Receiver higher utility when accepted. The Sender accepts proposals $a \leq \frac{1}{2}$ with probability $a+\frac{1}{2}$ because all type $t \leq a+d^{S}=a+\frac{1}{2}$ will accept. So, the Receiver maximizes his expected utility by solving

$$
\max _{a \in[0,1 / 2]} \operatorname{Pr}\{a \text { is accepted }\}\left(U^{R}(a)-U^{R}(\delta)\right)=\left(a+\frac{1}{2}\right)\left(\frac{5}{4}-a\right) .
$$

Therefore, in the size- 1 equilibrium, the Receiver proposes action $a=\frac{3}{8}$. All Sender types use the same message strategy, which is optimal for each type as it does not matter what they send because the Receiver will always propose $a=\frac{3}{8}$.

The game also has a size-2 equilibrium with actions $a_{1}=0$ and $a_{2}=\frac{1}{2}$. Sender types in $\left[0, \frac{1}{4}\right)$ could send the message "My type is low," inducing the 
Receiver to propose 0 . Types in $\left[\frac{1}{4}, 1\right]$ could send another message such as "My type is high," inducing the Receiver to propose $\frac{1}{2}$. When the Receiver receives the message "My type is low" he correctly infers that types are in the interval $\left[0, \frac{1}{4}\right)$ and proposes 0 , his most preferred outcome, as all types in $\left[0, \frac{1}{4}\right)$ accept 0 . If he receives the message "My type is high," he infers $t \in\left[\frac{1}{4}, 1\right]$. Again, proposals $a>1-d^{S}=\frac{1}{2}$ are never the Receiver's best response. Therefore, he solves

$$
\max _{a \in[0,1 / 2]} \operatorname{Pr}\left\{a \text { is accepted } \mid \mathrm{t} \in\left[\frac{1}{4}, 1\right]\right\}\left(U^{R}(a)-U^{R}(\delta)\right)=\frac{4}{3}\left(a+\frac{1}{4}\right)\left(\frac{5}{4}-a\right) .
$$

Indeed, $a=\frac{1}{2}$ is optimal.

Higher size equilibria cannot exist. Suppose they did, then the Receiver would play at least three equilibrium actions $0 \leq a_{1}<a_{2}<a_{3} \leq \frac{1}{2}$ with strictly positive probability. The corresponding Sender type partition would involve an interval of types $\left(t_{1}, t_{2}\right) \subset\left(0, \frac{1}{2}\right)$ inducing action $a_{2}$. However, if the Receiver believes types are in this interval, his best response is the action $a=0<a_{2}$ because $a=0$ is the Receiver's preferred outcome and all types in this interval will accept it. This establishes a contradiction.

How does bargaining power affect this picture? The maximum size equilibrium can be constructed as follows. The Receiver's highest equilibrium action $a_{n}$ satisfies $a_{n} \leq 1-d^{S}$ because actions greater than $1-d^{S}$ yield lower utility for the Receiver and are accepted by fewer Sender types than action $a=1-d^{S}$. For the same reason, each equilibrium action $a_{k}$, induced by types in the interval $\left(t_{k-1}, t_{k}\right)$, satisfies $a_{k} \leq t_{k}-d^{S}$ if $t_{k}>d^{S}$. This implies that indifference types $t_{k}>d^{S}$ receive the same utility as in the disagreement point. For type $t_{k}$ to be indifferent between equilibrium actions $a_{k}$ and $a_{k+1}$, the distance between the two actions must be at least $2 d^{S}$. So, starting with the highest equilibrium action, we can find the maximum size equilibrium by finding new equilibrium 
actions by consecutively subtracting $2 d^{S}$ until we go below zero. The lowest action in the maximum size equilibrium is always $a_{1}=0$.

For example, suppose we increase the Sender's bargaining power by moving her disagreement point's "harm" from $d^{S}=\frac{1}{2}$ to $d^{S}=\frac{1}{4}$. If we take $a_{n}=1-d^{S}$, this algorithm produces the following conjecture for a maximum size equilibrium for $d^{S}=\frac{1}{4}$ :

$$
\begin{aligned}
& a_{3}=1-d^{S}=\frac{3}{4} ; a_{2}=a_{3}-2 d^{S}=\frac{1}{4} ; a_{1}=0 \\
& {\left[t_{2}, t_{3}\right]=\left[\frac{1}{2}, 1\right] ; \quad\left[t_{1}, t_{2}\right]=\left[\frac{1}{8}, \frac{1}{2}\right] ; \quad\left[t_{0}, t_{1}\right]=\left[0, \frac{1}{8}\right]}
\end{aligned}
$$

It is readily verified that both players play a best response against each other, so that we have identified the maximum size equilibrium. Figure 2 represents the structure of this equilibrium.

Figure 2: The maximum size equilibrium for $d^{R}=\frac{5}{4}$ and $d^{S}=\frac{1}{4}$.

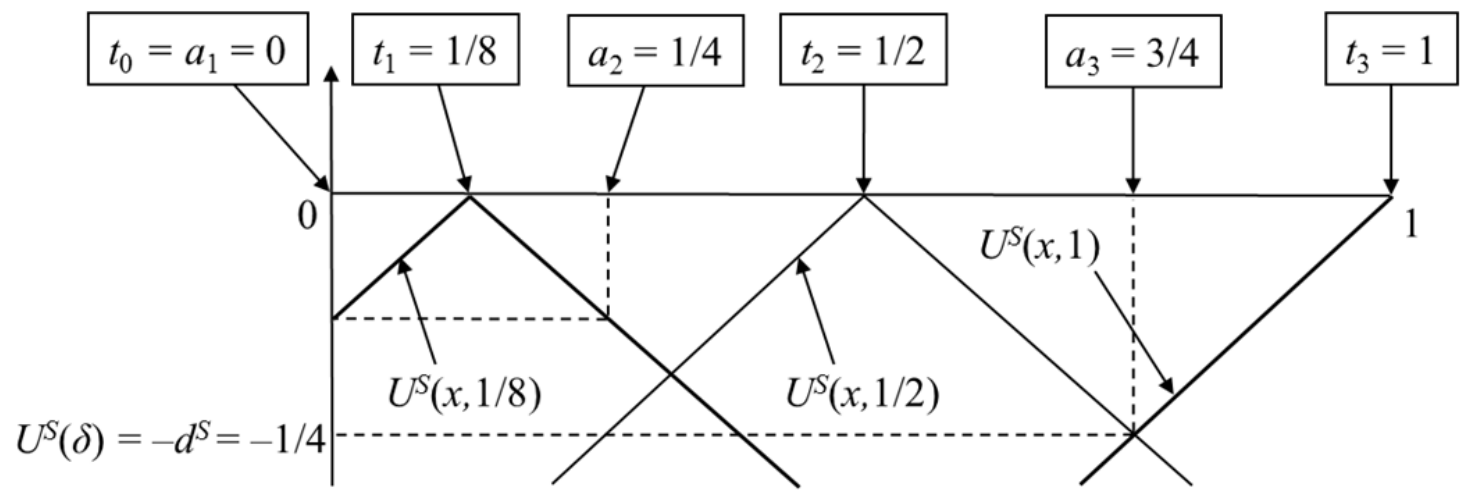

Observe that the maximum equilibrium size goes from 2 to 3 if we decrease the Sender's disagreement point's "harm" from $d^{S}=\frac{1}{2}$ to $d^{S}=\frac{1}{4}$. This finding illustrates our key result that the maximum information transmission possible in equilibrium increases with the Sender's relative bargaining power. 


\section{The general model}

A Sender and Receiver play the following game with an outcome in $X=\mathbb{R} \cup\{\delta\}$. First, the Sender privately observes her one dimensional type $t$. It is common knowledge that $t$ is drawn from the uniform distribution on the interval $[0,1] .{ }^{11}$ Second, the Sender sends a message $m \in M$, where $\mathbb{R} \subset M$. Third, the Receiver receives $m$ and proposes an action $a \in \mathbb{R}$. Finally, the Sender accepts or rejects $a$. If the Sender accepts [rejects], the proposed action $a[\delta]$ is the outcome of the game.

Let $U^{R}: X \rightarrow \mathbb{R}$ be the utility function of the Receiver and $U^{S}: X \times T \rightarrow \mathbb{R}$ that of the Sender. We model the players' bargaining power as the payoff of the disagreement point, $U^{R}(\delta)$ and $U^{S}(\delta)$, where we assume that neither depends on $t$. $U^{R}$ and $U^{S}$ satisfy the following assumptions:

(A1) $U^{R}$ is twice continuously differentiable, unimodal with a peak at 0 and concave on $\mathbb{R}$.

(A2) $U^{S}(\cdot, \cdot)$ is continuous, unimodal at $t$ for each $t$ on $\mathbb{R} ; U^{S}(x, t)$ is strictly increasing [decreasing] in $x$ for $x<t[x>t]$;

(A3) If a Sender type $t$ is indifferent between outcomes $x_{1}$ and $x_{2}>x_{1}$, then higher types than $t$ prefer $x_{2}$ and lower types prefer $x_{1}$.

Let the outcomes $\lambda\left(t, U^{S}(\delta)\right)<t$ and $\rho\left(t, U^{S}(\delta)\right)>t$ be the indifference points to the left respectively right of $t$ with respect to the disagreement point, i.e.

$$
U^{S}\left(\lambda\left(t, U^{S}(\delta)\right), t\right)=U^{S}\left(\rho\left(t, U^{S}(\delta)\right), t\right)=U^{S}(\delta)
$$

\footnotetext{
${ }^{11}$ Given that types $t$ are drawn from a smooth distribution function $F$, we can make the assumption of uniformly distributed types without further loss of generality: $t$ can be replaced by $\tilde{t} \equiv F(t)$, which is uniformly distributed on $[0,1]$. Of course, all other variables and assumptions should be redefined accordingly.
} 
Let $\lambda^{-1}\left(x, U^{S}(\delta)\right)$ and $\rho^{-1}\left(x, U^{S}(\delta)\right)$ be the inverse functions of $\lambda$ and $\rho$ with respect to $t$. Finally, we assume that

(A4) $\lambda$ and $\rho$ exist and are twice continuously differentiable and strictly increasing in $t$.

(A5) $\frac{\partial}{\partial x} \lambda^{-1} \geq \frac{\partial}{\partial x} \rho^{-1}, \frac{\partial^{2}}{\partial x^{2}} \lambda^{-1} \leq 0$ and $\frac{\partial^{2}}{\partial x \partial U^{S}(\delta)} \lambda^{-1}>0$.

If it is clear that we talk about a particular game with fixed $U^{S}(\delta)$, we will suppress the dependency on $U^{S}(\delta)$ and write $\lambda(t), \rho(t), \lambda^{-1}(x)$ and $\rho^{-1}(x)$. A simple condition on the Sender's preferences such that they satisfy (A2)-(A5) is the following:

$U^{S}(x, t)$ can be written as a function $f(t-x)$, for all $x$ in $\mathbb{R}, t$ in $[0,1]$, where $f$ is continuously differentiable, strictly increasing in $\mathbb{R}_{-}$, strictly decreasing in $\mathbb{R}_{+}$and for all $y \in \mathbb{R}$ there is a $z>0$ such that $f(-z)<y$ and $f(z)<y$. Finally, $U^{S}(\delta)<f(0)$.

Our results will often hold even when the Receiver's utility is not concave and (A5) does not hold, but these assumptions will greatly facilitate the construction of equilibria in Proposition 1 and prevents us from making tedious case distinctions. Figure 3 presents a graphical illustration of the model.

We now turn to characterizing the equilibrium set. The following lemmas are useful for establishing bounds on the equilibrium size.

Lemma 1 Any equilibrium of the game is a partition equilibrium.

Lemma 2 In equilibrium, $\lambda\left(t_{k-1}\right)<a_{k} \leq \lambda\left(t_{k}\right)$ for all $k=2, \ldots, n$.

Lemma 3 In equilibrium, $\rho\left(t_{k-1}\right) \leq a_{k}$ for $k=3, \ldots, n$. 
Lemma 4 Let $h(x) \equiv \lambda^{-1^{\prime}}(x)\left(U^{R}(x)-U^{R}(\delta)\right)+\left(\lambda^{-1}(x)-\rho^{-1}(x)\right) U^{R^{\prime}}(x)$, where a prime $\left({ }^{\prime}\right)$ denotes a derivative with respect to $x$. Let $\rho^{R}$ be the point $x>0$ where the Receiver is indifferent between $x$ and $\delta$. For all $U^{R}(\delta)$ and $U^{S}(\delta)$ there is a unique $x^{*} \in\left(0, \rho^{R}\right)$ such that $h\left(x^{*}\right)=0, h(x)>0$ for all $x<x^{*}$ and $h(x)<0$ for all $x>x^{*}$.

Figure 3: The general model

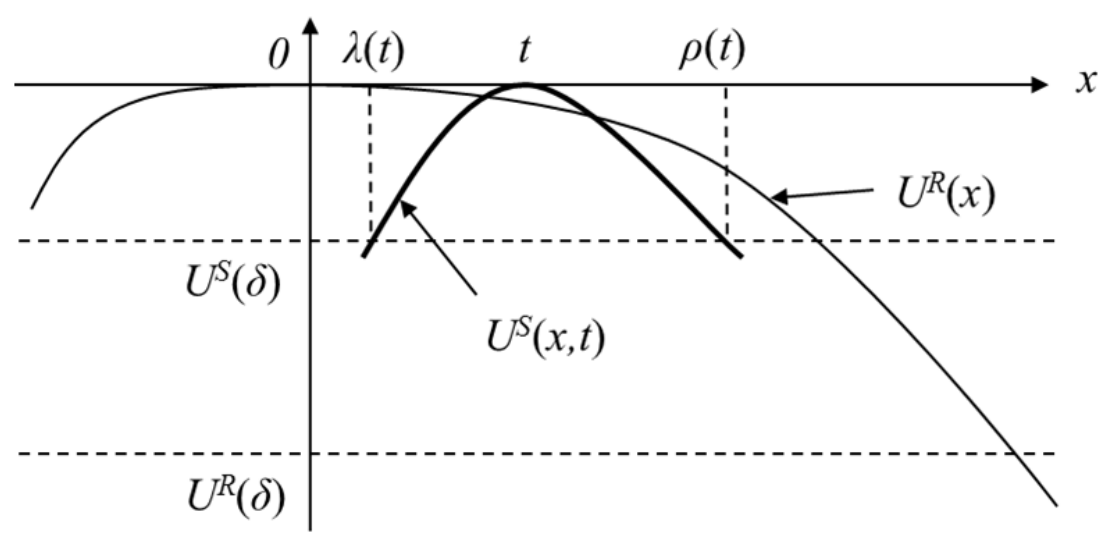

Intuitively, the highest type inducing an action $a_{k}>0$ (i.e., type $t_{k}$ ) must get zero payoff in equilibrium because otherwise, the Receiver can do better by proposing a lower action instead of $a_{k}$. This means that $a_{k+1}$ cannot be smaller than $\rho\left(\lambda^{-1}\left(a_{k}\right)\right)$, because otherwise type $t_{k}$ would prefer $a_{k+1}$ over $a_{k}$. Hence, there is a minimum distance between any two strictly positive equilibrium actions.

Define $\bar{x} \equiv \max \left\{0, \min \left\{\lambda(1), x^{*}\right\}\right\}$, where $x^{*}$ is defined in Lemma 4. We use the following algorithm to construct the maximum size equilibrium:

- Set the highest equilibrium action $a_{n}$ equal to $\bar{x}$;

- Iteratively add equilibrium actions $a_{k-1}=\lambda\left(\rho^{-1}\left(a_{k}\right)\right)$ until it 'does not fit anymore' $\left(\lambda\left(\rho^{-1}\left(a_{k}\right)\right)<0\right)$;

- Set $a_{1}=0$. 
In the proof of Proposition 1 in the appendix, we formalize this algorithm and show that it allows us to find the maximum size equilibrium.

Proposition 1 Let $\bar{n}$ denote the maximum equilibrium size. If $\lambda(1) \leq 0$, $\bar{n}=1$. Otherwise, if $\lambda^{-1}(0) \geq \rho^{-1}(\bar{x}), \bar{n}=2$, and if $\lambda^{-1}(0)<\rho^{-1}(\bar{x}), \bar{n} \geq 3$.

Proposition 1 is also interesting in the light of Matthews' (1989) result that the maximum equilibrium size is two in a veto-threats setting where the disagreement point is a point $\rho^{R}>0$ "on the line" independent of the Sender type t. From Proposition 1 we learn that Matthews' (1989) result hinges on the disagreement point being on the line. A disagreement point on the line implies that all Sender types that could close a deal with the Receiver have the same right indifference point $(\rho(t))$ as the highest point the Receiver would prefer to disagreement, i.e., $\rho(t)=\rho^{R}$ for all $t$. This limits the maximum equilibrium size to two for the following reason. Suppose, to the contrary, that the equilibrium size is at least three. Intuitively, the Receiver will never choose an equilibrium action at or above the disagreement point. Then, there is a Sender type $t_{2}$ that is indifferent between equilibrium actions $a_{2}$ and $a_{3}$ with $a_{2}<t_{2}<a_{3}<\rho^{R}$. As type $t_{2}$ obtains strictly higher utility from action $a_{2}$ than from the disagreement point so do types $t<t_{2}$. But then $a_{2}$ is not a best response for the Receiver because he can improve himself by choosing an action strictly below $a_{2}$, a contradiction. This limitation on equilibrium size is not present in our model, since $\rho(t)$ is increasing in $t$ and types exist with $\rho(t)<\rho^{R}$.

Now, we are ready to establish our main result on the relationship between power and information transmission:

Proposition 2 ( $i$ ) If the Receiver's bargaining power increases, $\bar{n}$ (weakly) decreases. (ii) If the Sender's bargaining power increases, $\bar{n}$ (weakly) increases. 
Hence, the higher the bargaining power of the Sender relative to that of the Receiver, the more information that can be transmitted in equilibrium. Increasing the Receiver's bargaining power decreases the highest possible action $\bar{x}$ the Receiver will propose in equilibrium because of his more attractive disagreement point, he can afford to be less generous with respect to the Sender. As a consequence, the number of equilibrium actions that 'fit' in this equilibrium becomes smaller (or remains the same). Increasing the Sender's bargaining power firstly increases $\bar{x}$ because the Receiver has to offer more generous proposals to keep high Sender types accepting it. In addition, increasing the Sender's power decreases the distance between equilibrium actions because $a-\lambda\left(\rho^{-1}(a)\right)$ becomes smaller for given $a$.

There are two features of the relation between power and information transmission that deserve further attention. First, Senders who induce 0 could reveal their type. We can use the number of equilibrium actions as a proxy for information transmission in so far as all Sender types who induce an equilibrium action $a$ send the same message. For each equilibrium outcome, always an equilibrium exists where this holds for all types. However, also pay-off equivalent equilibria exist where types inducing $a_{1}=0$ reveal their type. The reason is that they are protected by the fact that the Sender does not want to propose an action below 0. This means that Senders who are closely aligned to the Receiver can fully separate. In addition, this implies that if the Sender has no power (if $\lambda(1) \leq 0)$, then an equilibrium exists with full separation. In this case the Receiver always proposes 0 and Senders can send any message they want in equilibrium. Observe that they do not have an actual incentive to reveal their type.

Second, complete power in the Sender's hands may lead to less information transmission. If the Sender becomes very powerful $\left(U^{S}(\delta)\right.$ approaches $\left.U^{S}(t, t)\right)$, her incentive to communicate becomes small. In our model this is not relevant as long as $U^{S}(\delta) \leq U^{S}(t, t)$. However, one can imagine a model where sending a 
message has a small positive cost. In this case, increasing the power of the Sender will increase information transmission until the costs of communicating outweigh the benefits.

To further illustrate our findings, we return to our example in section 2. Observe that in this example, assumptions (A2)-(A5) are satisfied for the relevant range $x \in[0,1]$. The maximum equilibrium size $\bar{n}$ is equal to 1 if $d^{S} \geq 1$ because all Sender types will accept the Receiver's most preferred action $a=0$. Let $\bar{x}=\max \left\{0, \min \left\{d^{R}-2 d^{S}, 1-d^{S}\right\}\right\}$. If $d^{S}<1$ and $\bar{x}<2 d^{S}$, the maximum equilibrium size is 2 .

Otherwise, the maximum equilibrium size is at least 3 and the highest possible equilibrium action equals $\bar{x}$. The minimum distance between consecutive strictly positive equilibrium actions $a_{k-1}$ and $a_{k}$ is equal to $a_{k}-\lambda\left(\rho^{-1}\left(a_{k}\right)\right)=2 d^{S}$. Therefore, the maximum equilibrium size equals $\bar{n}=\left\lceil\frac{\bar{x}}{2 d^{S}}\right\rceil+1$, where $\lceil$.$\rceil is the ceiling function. For d^{S}<1, \bar{n}=\left\lceil\frac{1}{2}+\frac{1}{2 d^{S}}\right\rceil$ if $d^{R}>d^{S}+1$, and $\bar{n}=\left\lceil\frac{d^{R}}{2 d^{S}}\right\rceil$ if $d^{R} \leq d^{S}+1$.

Note that $\bar{n}$ is decreasing in $d^{S}$ and increasing in $d^{R}$. If the Receiver has very little power $\left(d^{R}>d^{S}+1\right)$, the maximum size only depends on (and is increasing in) the power of the Sender. If the Receiver has some power as well $\left(d^{R} \leq d^{S}+1\right)$, then the maximum size $\bar{n}$ increases in the relative power of the Sender, i.e., $\bar{n}$ jumps to a higher level if $\left\lceil\frac{d^{R}}{2 d^{S}}\right\rceil$ increases sufficiently. As the power of the Sender relative to that of the Receiver becomes large, the maximum equilibrium size also becomes large. 


\section{Conclusion}

In this paper, we examined how power shapes communication under information asymmetry. Our interest was to explore the levels of clarity that are likely to arise between agents with different levels of power. In a bargaining model with asymmetric information, we showed that clarity is indeed a privilege of the powerful. When negotiating an outcome, an informed bargainer with (relatively) little bargaining power cannot afford to reveal too much information, as that can be used against her. How much information can be transmitted in equilibrium depends crucially on the relative power of the informed party, the Sender: less information can be transmitted in equilibrium if either the Sender's power decreases or the Receiver's power increases. ${ }^{12}$

In addition to providing a proof-of-principle, our analysis has testable implications for communication and outcomes in the field. ${ }^{13}$ One application concerns contract negotiations between employers and employees. Here, asymmetric information and bargaining power play a significant role. One can think of an employee's preference for the work-life balance (salary versus flexibility) or the type of activities she is required to do. For instance, when a department negotiates with a potential new professor about her administrative and teaching duties, the preference of the professor for administration versus teaching are typically unknown. One implication of our analysis is that when the employee has more bargaining power, she will be able to convey her preferences more precisely. As a measure of bargaining power one could use the level of skill of employees or the unemployment rate in a given sector and/or year. Our model predicts that as information transmission increases, the variety of outcomes also increases. As a consequence, our model predicts that the variety

\footnotetext{
${ }^{12}$ Che and Kartik (2009) find that difference of opinion (i.e. how much prior beliefs are aligned) can also be a crucial factor in determining what and how much information transmission is transmitted.

${ }^{13}$ In addition, in De Groot Ruiz, Offerman and Onderstal (2011b) we test our predictions in a controlled laboratory experiment and find that the relative power of the Sender increases information transmission.
} 
of labor contracts in a specific job market should be increasing with the employment rate (in the sector) and the skill-level required for the job.

Another application where our model has testable implications is negotiations between a competition authority and two firms planning a merger. If the merger creates or strengthens market power in the relevant market, the competition authority can demand remedies, such as requiring the firms to sell some production-lines to a third party. Firms always want as few remedies as possible. Preferences of competition authorities are less clear, as they have to weigh economies of scale against market power. ${ }^{14}$ Competition authorities provide information about their preferences to firms before they submit their final proposal, often already in the pre-notification phase. Our model predicts that the variability of the proposals a competition authority receives is increasing in its power. A competition authority with little power always gets the same kind of proposal (across comparable cases), for instance a proposal without remedies. A competition authority with more power can expect to receive proposals that sometimes include remedies and sometimes not. Indicators exist about the strength of competition authorities, such as the OECD's Competition Law and Policy (CLP) indicators (Høj, 2007) or those developed by Voigt (2006) for a broader set of countries. Such indicators include the formal and factual independence of competition authorities. These proxies for bargaining power could be related to how often final proposals include remedies (or even to the variety of remedies included). A relevant comparison would be between competition authorities in (old) EU member states and the US with those in Latin America or Eastern Europe. ${ }^{15}$ Testing the empirical implications of the model might be a worthwhile avenue for future research.

\footnotetext{
${ }^{14}$ Another possible trade-off for competition authorities concerns collusion (Compte, Jenny and Rey, 2002). A merger reduces the number of competing firms, which can make collusion easier. However, if a merger involves the largest firm, it can also increase asymmetries in capacity constraints, making collusion more difficult.

${ }^{15}$ For comparative work on competition authorities in Latin America, see Schatan and Rivera (2008) and Qaqaya and Lipmile (2008); For competition authorities in Europe, see Cseres (2010).
} 
Another aspect that would be interesting for further research are the effects of delegation in the present model, as delegation yields interesting results in other cheap talk settings (Dessein, 2002; Marino, 2007; Alonso and Matouschek, 2008).

\section{Appendix: Proofs}

Proof of Lemma 1 Let $\sigma^{*}$ be an equilibrium. First, we show that the set of equilibrium actions is finite. Suppose the Receiver plays at least three actions in equilibrium and let $a<a^{\prime}$ be two strictly positive equilibrium actions. Let $\bar{t}(a)$ be the supremum of types that induce action $a$. Then $0<a \leq \lambda(\bar{t}(a))$, because otherwise the Receiver would be better off by playing $\lambda(\bar{t}(a))$ instead of $a$. Furthermore, $a^{\prime} \geq \rho(\bar{t}(a))$, because otherwise $U^{S}\left(a^{\prime}, \bar{t}(a)\right)$ $>U^{S}(a, \bar{t}(a))$. This means that $a^{\prime}-a \geq \rho(\bar{t}(a))-\lambda(\bar{t}(a))$. Consequently, an upper bound on the number of equilibrium actions is $1+1 / \eta$, where $\eta=\min _{t \in[0,1]}\{\rho(t)-\lambda(t)\}$. This means that the set of equilibrium actions, $A^{*}$, is finite. Hence, we can write $A^{*}=\left\{a_{1}, a_{2}, \ldots, a_{n}\right\}$ with $a_{1}<a_{2}<\ldots<a_{n}$.

Second, (A2)-(A3) imply that for each consecutive action pair $a_{k}, a_{k+1}$ a triple of types $t_{k-1}<t_{k}<t_{k+1}$ exists such that

$$
\begin{aligned}
& U^{S}\left(a_{k}, t_{k}\right)=U^{S}\left(a_{k+1}, t_{k}\right) \text { and } \\
& a_{l} \in \arg \max _{a \in A^{*}} U^{S}(a, t) \text { iff } t \in\left[t_{l-1}, t_{l}\right] \text { for } l=k, k+1 .
\end{aligned}
$$

Consequently, a partition of the type space $0=t_{0}<t_{1}<\cdots<t_{n-1}<t_{n}=1$ exists such that for each $k$ all types in $\left(t_{k-1}, t_{k}\right)$ induce the same action $a_{k}$ and that $k \neq l$ implies that $a_{k} \neq a_{l}$. Q.E.D. 
Proof of Lemma 2 Note that by construction, $a_{1}<a_{2}<\ldots<a_{n}$. It must be the case that $a_{k}>a_{1} \geq 0$ for all $k=2, \ldots, n$. Moreover, $a_{k}>\lambda\left(t_{k}\right)$ cannot occur in equilibrium, because if the Sender type is in the interval $\left[t_{k-1}, t_{k}\right]$, the Receiver is better off by offering $a=\lambda\left(t_{k}\right)$ instead of $a=a_{k}$. Finally, $a_{k}>\lambda\left(t_{k-1}\right)$ because otherwise none of the types in $\left[t_{k-1}, t_{k}\right]$ will accept $a_{k}$. Q.E.D.

Proof of Lemma 3 The proof is by contradiction. Lemma 2 shows that $a_{k-1} \leq \lambda\left(t_{k-1}\right)$, so that type $t_{k-1}$ 's utility is equal to the utility of the disagreement point if she induces $a_{k-1}$. Suppose that $\rho\left(t_{k-1}\right)>a_{k}$. Then type $t_{k-1}$ is strictly better off inducing $a_{k}$ instead of $a_{k-1}$. This constitutes a contradiction, because types just below $t_{k-1}$ would strictly prefer sending $a_{k}$ instead of $a_{k-1}$, while they induce $a_{k-1}$ in equilibrium. Q.E.D.

Proof of Lemma 4 Assumptions (A4) and (A5) imply that all terms in $h^{\prime}(x)=\lambda^{-1^{\prime \prime}}(x)\left(U^{R}(x)-U^{R}(\delta)\right)+\lambda^{-1^{\prime}}(x) U^{R^{\prime}}(x)+\left(\lambda^{-1^{\prime}}(x)-\rho^{-1^{\prime}}(x)\right) U^{R^{\prime}}(x)+\left(\lambda^{-1}(x)-\rho^{-1}(x)\right) U^{R \prime \prime}(x)$ are negative on $\left[0, \rho^{R}\right)$ for all values of $U^{R}(\delta)$ and $U^{S}(\delta)$. Therefore, $h$ is strictly decreasing on $\left[0, \rho^{R}\right)$. The result immediately follows by the intermediate value theorem since $h$ is continuous, $h(0)>0$ and $h(x)<0$ for all $x \geq \rho^{R}$. Q.E.D.

Proof of Proposition 1 If $\lambda(1) \leq 0$, it is readily verified that the game only has a size-1 equilibrium in which $t_{0}=0, t_{1}=1$, and $a_{1}=0$. We first establish that no equilibrium exists where the equilibrium size is at least 3 $(n \geq 3)$ and where $a_{n}>\bar{x}$. Suppose, to the contrary, that $a_{n}>\bar{x}$. Observe that $a_{n} \leq \min \left\{\lambda(1), \rho^{R}\right\}$. The Receiver who believes $t$ to be uniformly distributed on $\left[t_{n-1}, 1\right]$ solves 


$$
\max _{a \in\left[\lambda\left(t_{n-1}\right), \lambda(1)\right]} E U^{R}(a)=\frac{\lambda^{-1}(a)-\max \left\{t_{n-1}, \rho^{-1}(a)\right\}}{1-t_{n-1}}\left(U^{R}(a)-U^{R}(\delta)\right)
$$

where the first term refers to the conditional probability that the Sender accepts. Because $n \geq 3, a_{n} \geq \rho\left(t_{n-1}\right)$ according to Lemma 3. However, $a_{n} \geq \rho\left(t_{n-1}\right)$ cannot be optimal because by (A1), (A4) and Lemma 4, for $a>\rho\left(t_{n-1}\right)$,

$$
\begin{aligned}
\frac{\partial E U^{R}(a)}{\partial a} & \cong\left(\lambda^{-1^{\prime}}(a)-\rho^{-1^{\prime}}(a)\right)\left(U^{R}(a)-U^{R}(\delta)\right)+\left(\lambda^{-1}(a)-\rho^{-1}(a)\right) U^{R^{\prime}}(a) \\
& =h(a)-\rho^{-1^{\prime}}(a)\left(U^{R}(a)-U^{R}(\delta)\right)<0
\end{aligned}
$$

and for $a$ smaller than but close to $\rho\left(t_{n-1}\right)$,

$$
\begin{aligned}
\frac{\partial E U^{R}(a)}{\partial a} & \cong \lambda^{-1^{\prime}}(a)\left(U^{R}(a)-U^{R}(\delta)\right)+\left(\lambda^{-1}(a)-t_{n-1}\right) U^{R^{\prime}}(a) \\
& =h(a)+\left(\rho^{-1}(a)-t_{n-1}\right) U^{R^{\prime}}(a)<0 .
\end{aligned}
$$

Therefore, it follows that $\bar{x}$ is the highest possible equilibrium action if the equilibrium size is at least 3 .

Now, we show that if $\lambda^{-1}(0) \geq \rho^{-1}(\bar{x})$, the maximum size equilibrium has size 2. Suppose, in constrast, that the maximum equilibrium size is at least 3 . Then,

$$
t_{2} \leq \rho^{-1}\left(a_{3}\right) \leq \rho^{-1}(\bar{x}) \leq \lambda^{-1}(0)
$$

where the first inequality follows from Lemma 3. But then a contradiction is established because all types $t \leq t_{2}$ will accept the Receiver's most preferred 
outcome $a=0$, which is in conflict with the assumption that types in the interval $\left[t_{1}, t_{2}\right]$ induce an action $a_{2}>0$. A size-2 equilibrium for $\lambda^{-1}(0) \geq \rho^{-1}(\bar{x})$ can be readily constructed by setting $t_{0}=0, t_{2}=1, a_{1}=0$, and $t_{1}$ and $a_{2}$ simultaneously solving

$$
\begin{aligned}
& a_{2} \in \arg \max _{a \in[0, \lambda(1)]}\left(U^{R}(a)-U^{R}(\delta)\right)\left(\lambda^{-1}(a)-\max \left\{t_{1}, \rho^{-1}(a)\right\}\right) \text { and } \\
& U^{S}\left(t_{1}, a_{2}\right)=U^{S}\left(t_{1}, 0\right) .
\end{aligned}
$$

These two equations have a solution. Let $\tilde{t}_{1}(a)$ be the point $t$ where $U^{S}(a, t)=U^{S}(0, t)$. Then there exists a continuous function $a_{2}(a)$ such that $a_{2}(a) \in \arg \max _{a \in[0, \lambda(1)]}\left(U^{R}(a)-U^{R}(\delta)\right)\left(\lambda^{-1}(a)-\max \left\{\tilde{t}_{1}(a), \rho^{-1}(a)\right\}\right)$. Observe that $a_{2}(0) \geq 0$ and $a_{2}(1) \leq \lambda(1)$. Hence $a_{2}(a)$ has a fixed point on $[0,1]$.

Finally, if $\lambda^{-1}(0)<\rho^{-1}(\bar{x})$, the maximum size equilibrium can be established using the following algorithm:

1. Let $\bar{n}$ be some natural number. Define $t_{\bar{n}}=1, t_{\bar{n}-1}=\rho^{-1}(\bar{x}), a_{\bar{n}}=\bar{x}$, and assign value $\bar{n}-2$ to counter $k$.

2. Define $t_{k} \in(0,1]$ such that $\rho\left(t_{k}\right)=\lambda\left(t_{k+1}\right)$. If such a $t_{k}$ does not exist, go to step 3. Otherwise, $a_{k+1}=\lambda\left(t_{k+1}\right), k \leftarrow k-1$ and return to step 2 .

3. Relabel $t_{k+1}, \ldots, t_{\bar{n}}$ and $a_{k+2}, \ldots, a_{\bar{n}}$ such that $k \leftarrow 1, k+1 \leftarrow 2, \ldots, \bar{n} \leftarrow n$. Let $t_{0}=0, \quad a_{1}=0, \quad a_{2}=\lambda\left(t_{2}\right) \quad$ and define $t_{1}$ such that $U^{S}\left(t_{1}, 0\right)=U^{S}\left(t_{1}, a_{2}\right)$.

In step $2, a_{k+1}$ follows from the requirement that it maximizes the Receiver's expected utility over and above his utility from the disagreement point, $\left(U^{R}(a)-U^{R}(\delta)\right) \operatorname{Pr}\left\{U^{S}(a, t)>U^{S}(\delta, t) \mid t \in\left[t_{k}, t_{k+1}\right]\right\}$, which in our case implies

$$
a_{k+1} \in \arg \max _{a \in[0,1]}\left(U^{R}(a)-U^{R}(\delta)\right)\left(\min \left\{t_{k+1}, \lambda^{-1}(a)\right\}-\max \left\{t_{k}, \rho^{-1}(a)\right\}\right) .
$$


Due to Lemma 2, it must hold that $a_{k+1} \leq \lambda\left(t_{k+1}\right)$ for all $k=1, \ldots, n-1$. Since $\rho\left(t_{k}\right)=\lambda\left(t_{k+1}\right)$, we have $a_{k+1} \in \arg \max _{a \in\left[\lambda\left(t_{k}\right), \lambda\left(t_{k+1}\right)\right]}\left(U^{R}(a)-U^{R}(\delta)\right)\left(\lambda^{-1}(a)-t_{k}\right)$.

From Lemma 4, it follows that

$$
\lambda^{-1^{\prime}}(a)\left(U^{R}(a)-U^{R}(\delta)\right)+\left(\lambda^{-1}(a)-t_{k}\right) U^{R^{\prime}}(a)=h(a)+\left(\rho^{-1}(a)-t_{k}\right) U^{R^{\prime}}(a)>0
$$

for $\lambda\left(t_{k}\right) \leq a<\lambda\left(t_{k+1}\right)=\rho\left(t_{k}\right)<\bar{x}$. Indeed, $a_{k+1}=\lambda\left(t_{k+1}\right)$ is optimal.

Analogously, it follows that $a_{\bar{n}}=\bar{x}$ in step 1 and $a_{2}=\lambda\left(t_{2}\right)$ in step 3 are best responses for the Receiver. Because $\lambda(t)$ and $\rho(t)$ are monotonic by assumption, this algorithm results in the tightest partition which satisfies the equilibrium properties from Lemma 2 so that it implements an equilibrium of the highest possible size. Q.E.D.

Proof of Proposition 2 We first prove (i). Suppose the Receiver's bargaining power $U^{R}(\delta)$ increases from $\Pi$ to $\breve{\Pi}$. Now,

$$
\begin{aligned}
& \lambda^{-1^{\prime}}(\bar{x})\left(U^{R}(\bar{x})-\breve{\Pi}\right)+\left(\lambda^{-1}(\bar{x})-\rho^{-1}(\bar{x})\right) U^{R^{\prime}}(\bar{x}) \\
= & \lambda^{-1^{\prime}}(\bar{x})\left(U^{R}(\bar{x})-\Pi\right)+\left(\lambda^{-1}(\bar{x})-\rho^{-1}(\bar{x})\right) U^{R^{\prime}}(\bar{x})+\lambda^{-1^{\prime}}(\bar{x})(\Pi-\breve{\Pi})<0 .
\end{aligned}
$$

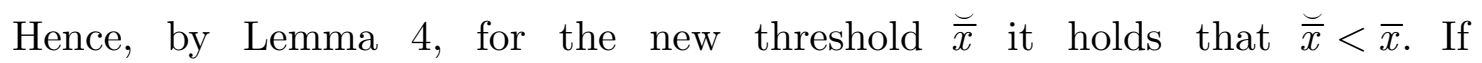
$\lambda^{-1}(0) \geq \rho^{-1}(\bar{x})$, observe that $\rho^{-1}(\bar{x}) \leq \rho^{-1}(\bar{x}) \leq \lambda^{-1}(0)$. If $\lambda^{-1}(0)<\rho^{-1}(\bar{x})$, then with the above algorithm we can get a maximum size equilibrium with partition $0=\breve{t}_{0}<\breve{t}_{1}<\cdots<\breve{t}_{\breve{n}}=1$. Furthermore, when running the algorithm proposed in Proposition 1, all new threshold types will be lower than for the original game $\left(\breve{t}_{\breve{n}_{-k}}<t_{\breve{n}_{-k}}\right.$ for all $\left.1 \leq k<\breve{n}\right)$. Therefore, the maximum size of the equilibrium decreases if the Receiver's bargaining power increases. 
Now we proof $(i i)$. Suppose that the Sender's bargaining power $U^{S}(\delta)$ increases from $\Sigma$ to $\hat{\Sigma}$. If $\lambda(1, \Sigma) \leq 0$, observe that $\lambda(1, \hat{\Sigma})>\lambda(1, \Sigma)$. If $\lambda^{-1}(0, \Sigma) \geq \rho^{-1}(\bar{x}, \Sigma)$, note that $\lambda^{-1}(0, \hat{\Sigma})-\rho^{-1}(\bar{x}, \hat{\Sigma})<\lambda^{-1}(0, \Sigma)-\rho^{-1}(\bar{x}, \Sigma)$, and $\rho^{-1}(\bar{x}, \hat{\Sigma})>\rho^{-1}(\bar{x}, \Sigma)$, since $\lambda^{-1}(0, \hat{\Sigma})<\lambda^{-1}(0, \Sigma)$ and $\rho^{-1}(\bar{x}, \hat{\Sigma})>\rho^{-1}(\bar{x}, \Sigma)$.

Finally, let $\lambda^{-1}(0, \Sigma)<\rho^{-1}(\bar{x}, \Sigma)$. Analogous to the proof of $(i)$, we can show that increasing the Sender's bargaining power results in a higher $\hat{\bar{x}}$ :

$$
\begin{aligned}
& \lambda^{-1^{\prime}}(\bar{x}, \hat{\Sigma})\left(U^{R}(\bar{x})-U^{R}(\delta)\right)+\left(\lambda^{-1}(\bar{x}, \hat{\Sigma})-\rho^{-1}(\bar{x}, \hat{\Sigma})\right) U^{R^{\prime}}(\bar{x}) \\
& \left.\left.\left.=\lambda^{-1^{\prime}}(\bar{x}, \Sigma)\right)\left(U^{R}(\bar{x})-U^{R}(\delta)\right)+\left(\lambda^{-1}(\bar{x}, \Sigma)\right)-\rho^{-1}(\bar{x}, \Sigma)\right)\right) U^{R^{\prime}}(\bar{x}) \\
& +\left(\lambda^{-1^{\prime}}(\bar{x}, \hat{\Sigma})-\lambda^{-1^{\prime}}(\bar{x}, \Sigma)\right)\left(U^{R}(\bar{x})-U^{R}(\delta)\right) \\
& +\left(\lambda^{-1}(\bar{x}, \hat{\Sigma})-\lambda^{-1}(\bar{x}, \Sigma)-\rho^{-1}(\bar{x}, \hat{\Sigma})+\rho^{-1}(\bar{x}, \Sigma)\right) U^{R^{\prime}}(\bar{x}) \\
& >0 .
\end{aligned}
$$

Observe for the third term in the middle expression that $\lambda^{-1^{\prime}}(\bar{x}, \hat{\Sigma})>\lambda^{-1^{\prime}}(\bar{x}, \Sigma)$ by (A5); and for fourth term that $\quad \lambda^{-1}(\bar{x}, \hat{\Sigma})<\lambda^{-1}(\bar{x}, \Sigma)$ and $\rho^{-1}(\bar{x}, \hat{\Sigma})>\rho^{-1}(\bar{x}, \Sigma)$ due to the shrinking interval of points the Sender accepts when her power increases. Hence, with the above algorithm we can get a new maximum size equilibrium partition $0=\hat{t}_{0}<\hat{t}_{1}<\cdots<\hat{t}_{\hat{n}}=1$. There are now two reasons why all threshold types will be higher than for the original game $\left(\hat{t}_{\hat{n}-k}>t_{n-k}\right.$ for all $\left.1 \leq k<n\right)$, possibly resulting in extra equilibrium actions. First, the highest equilibrium action can be higher, since $\hat{\bar{x}}>\bar{x}$. Second, the equilibrium actions will be closer together, since for each type it holds that $\lambda(t, \Sigma)<\lambda(t, \hat{\Sigma})$ and $\rho(t, \Sigma)>\rho(t, \hat{\Sigma})$. Hence, the number of equilibrium actions in the maximum size equilibrium is (weakly) higher when $U^{S}(\delta)=\hat{\Sigma}$ than when $U^{S}(\delta)=\Sigma$. Q.E.D. 


\section{References}

Agranov, M., \& Schotter, A. (2011). Language and Leadership: an Experimental Study of Ambiguity and Vagueness in the Announcement Game. Working paper, New York University.

Alonso, R., \& Matouschek, N. (2008). Optimal delegation. Review of Economic Studies, 75, 259-293.

Ausubel, L. M., Cramton, P., \& Deneckere, R. J. (2002). Bargaining with incomplete information. In R. J. Aumann, \& S. Hart (Eds.), Handbook of Game Theory with Economic Applications (Vol. 3, pp. 1897-1945). Amsterdam: North-Holland.

Baer, J. L. (1976). How to be an Assertive (Not Aggressive) Woman in Life, Love, and on the Job: A Total Guide to Self-Assertiveness. New York, NY: New American Library.

Blume, A., Kim, Y.-G., \& Sobel, J. (1993). Evolutionary Stability in Games of Communication. Games and Economic Behavior, 5, 547-575.

Butler, P. E. (1976). Self-Assertion For Women: A Guide to Becoming Androgynous. New York, NY: Canfield.

Calvó-Armengol, A. (2001). Bargaining Power in Communication Networks. Mathematical Social Sciences, 41, 49-87.

Che, Y.-K., \& Kartik, N. (2009). Opinions as Incentives. Journal of Political Economy, 117, 815-860.

Chen, Y., Kartik, N., \& Sobel, J. (2008). Selecting Cheap Talk Equilibria. Econometrica, 76, 117-136.

Cheng, W., \& Warren, M. (2003). Inexplicitness, Indirectness and Vagueness Made Clearer. Pragmatics, 13, 381-400.

Compte, O., Jenny, F., \& Rey, P. (2002). Capacity Constraints, Mergers and Collusion. European Economic Review, 46, 1-29.

Crawford, V., \& Sobel, J. (1982). Strategic Information Transmission. Econometrica, 50, 1431-1451. 
Cseres, K. (2010). Comparing Laws in the Enforcement of EU and National Competition Laws. European Journal of Legal Studies, 3, 7-44.

De Groot Ruiz, A. W., Offerman, T., \& Onderstal, S. (2011a). Power and the Privilege of Clarity: An Analysis of Bargaining Power and Information Transmission. Working paper, University of Amsterdam.

De Groot Ruiz, A. W., Offerman, T., \& Onderstal, S. (2011b). An Experimental Study of Credible Deviations and ACDC. Working paper, University of Amsterdam.

Dessein, W. (2002). Authority and Communication in Organizations. Review of Economic Studies, 69, 811-838.

Farrell, J. (1993). Meaning and Credibility in Cheap-Talk Games. Games and Economic Behavior, 5, 514-531.

Farrell, J., \& Gibbons, R. (1989). Cheap Talk can Matter in Bargaining. Journal of Economic Theory, 48, 221-237.

Gudykunst, W. B., \& Lee, C. L. (2003). Cross-cultural Communication Theories. In W. B. Gudykunst (Ed.), Cross-cultural and Intercultural Communication. Thousand Oaks, CA: Sage Publications, Inc.

Henley, N. M., \& Kramarae, C. (2001). Gender, Power, and Miscommunication. In D. M. Huschka (Ed.), Feminism in the Study of Religion: A Reader (pp. 34-60). Bodmin, Cornwall: MPG Books Ltd.

Høj, J. (2007). Competition Law and Policy Indicators for the OECD countries. OECD Economics Department Working Papers No. 568.

Kartik, N. (2009). Strategic Communication with Lying Costs. Review of Economic Studies, 76, 1359-1395.

Kartik, N., Ottaviani, M., \& Squintani, F. (2007). Credulity, Lies and Costly Talk. Journal of Economic Theory, 134, 93-116.

Keating, E. (2009). Power and Pragmatics. Language and Linguistics Compass, 3(4), 996-1009.

Kipnis, D., Schmidt, S. M., \& Wilkinson, I. (1980). Intraorganizational Influence Tactics: Explorations in Getting One's Way. Journal of Applied Psychology, 65(4), 440-452. 
Kohlberg, E., \& Mertens, J.-F. (1986). On the Strategic Stability of Equilibria. Econometrica, 54, 1003-1037.

Maltz, D. N., \& Bork, R. A. (1982). A Cultural Approach to Male-Female Miscommunication. In J. Gumperz (Ed.), Language and Social Identity (pp. 195-216). Cambridge: Cambridge University Press.

Marino, A. M. (2007). Delegation versus Veto in Organizational Games of Strategic Communication. Journal of Public Economic Theory, 9, 979992.

Matthews, S. A. (1989). Veto Threats: Rhetoric in a Bargaining Game. Quarterly Journal of Economics, 104, 347-369.

Matthews, S. A., \& Postlewaite, A. (1989). Pre-Play Communication in TwoPerson Sealed-Bid Double Auctions. Journal of Economic Theory, 48, 238-263.

Matthews, S. A., Okuno-Fujiwara, M., \& Postlewaite, A. (1991). Refining Cheap-Talk Equilibria. Journal of Economic Theory, 55, 247-273.

Pitchik, C., \& Schotter, A. (1987). Honesty in a Model of Strategic Information Transmission. American Economic Review, 77, 1032-1036.

Qaqaya, H., \& Lipimile, G. (2008). The Effects of Anti-competitive Business Practices on Developing Countries and their Development Prospects. Geneva: United Nations Conference on Trade and Development.

Rabin, M. (1990). Communication between Rational Agents. Journal of Economic Theory, 51, 144-170.

Rabin, M., \& Sobel, J. (1996). Deviations, Dynamics and Equilibrium Refinements. Journal of Economic Theory, 68, 1-25.

Schatan, C., \& Rivera, E. (Eds.). (2008). Competition Policies in Emerging Economies. Lessons and Challenges from Central America and Mexico. Ottowa: Springer/United Nations ECLAC/ IDRC.

Selten, R. (1975). Reexamination of the Perfectness Concept for Equilibrium Points in Extensive Games. International Journal of Game Theory, 4, $25-55$. 
Sobel, J. (1985). A Theory of Credibility. Review of Economic Studies, 52, 557573.

Voigt, S. (2006). The Economic Effects of Competition Policy ñ Cross-Country Evidence Using Four New Indicators. ICER Working Paper Series No. 20.

Yukl, G., \& Falbe, C. M. (1990). Influence Tactics and Objectives in Upward, Downward, and Lateral Influence Attempts. Journal of Applied Psychology, 75, 2, 132-140. 